\title{
ON-LAND COMMUNITY-BASED AEROBIC AND STRENGTH TRAINING PROGRAM FOR CHILDREN WITH CEREBRAL PALSY
}

\author{
Michelle Kelly \\ David Legg \\ Mount Royal College, Calgary, Canada
}

\begin{abstract}
Research has been conducted on the effects of strength training for children with cerebral palsy but there are large gaps in our understanding of the nature of aerobic limitations and the effects of exercise interventions on function. There is also a paucity of research on the effects of combined interventions involving both strength and aerobic training. For these reasons this study was pursued with the question being what effects, specific to energy expenditure, muscle strength, and perceived satisfaction and perceived performance of a functional motor goal resulted from a community exercise program using both aerobic and anaerobic components for children with cerebral palsy. Six 8-12 year old children with ambulatory cerebral palsy (able to walk independently $>25$ meters) participated in four separate ten-week, three-times-per-week exercise and fitness activity programs. All six children demonstrated improvements in energy expenditure and perceived satisfaction while scores were variable for muscle strength. These results offer support for future investigation to explore the potential for aerobic and strength training interventions for children with cerebral palsy.
\end{abstract}

KEYWORDS: Aerobic, strength, exercise, training, and cerebral palsy.

\section{INTRODUCTION}

There is growing concern regarding inactivity of children in North America (Canadian Pediatric Society, 2002) because of its link to health issues such as diabetes, osteoporosis, and obesity (American Academy of Pediatrics, 2003). Children with cerebral palsy are then at an even greater risk because they are less active than their typically developing peers (van den Berg-Emons, Saris, de Barbanson, Westerterp, Huson, \& van Baak, 1995). Strauss, Cable and Shavelle (1999) for instance described a significant excess of mortality in children with cerebral palsy due to circulatory disease and these findings were attributed, in part, to reduced levels of physical activity. To address this, participation in physical activity for children with cerebral palsy is being actively promoted to assist in improving health and reducing risks associated with secondary conditions (Fowler, Kolobe, Damiano, Thorpe, Morgan, \& Brunnstrom, 2007). More specifically, group sport and fitness activities are promoted to help increase levels of physical activity in addition to social interaction (Canadian Pediatric Society, 2002).

\section{REVIEW OF LITERATURE}

Evidence suggests that progressive resistance exercise (PRE) for children with cerebral palsy can increase muscle strength without increasing spasticity or reducing range of motion (Taylor, Dodd, \& Damiano, 2005). Effects of PRE on motor function and energy expenditure, however, are less conclusive (Taylor et al., 2005). Individual studies have also demonstrated improvements in dimensions $\mathrm{D}$ and/or $\mathrm{E}$ of the Gross Motor Function Measure (GMFM) (i.e. standing, walking, and running skills) (Damiano \& Abel, 1998; MacPhail \& Kramer, 1995). These studies reported effects for subjects 6 to 20 years old following PRE three-times-per-week for six to eight weeks. Improvements on other aspects of activity such as walking velocity and Energy Expenditure Index (EEI) scores, however, are variable. The EEI represents a ratio of resting and walking heart rate to walking velocity and results in units of beats per meter (Rose, 
Medeiros \& Parker, 1985) and has been used as an indicator of energy expenditure for children with cerebral palsy in past research (Eagleton, Iams, McDowell, Morrison, \& Evans, 2004; Schlough, Nawoczenski, Case, Nolan \& Wigglesworth, 2005).

Change on the walking velocity of children with cerebral palsy following PRE training have been demonstrated by two studies (Eagleton et al, 2004; Damiano \& Abel, 1998), however, another reported no effect (MacPhail \& Kramer, 1995). This inconsistency may be the result of the way in which PRE was applied where observed change in velocity scores applied resistance to the child's two weakest muscles (identified on assessment) (Damiano \& Abel, 1998), or to muscles selected specifically for their role in gait (Eagleton et al., 2004) as opposed to the hamstring and quadriceps muscles alone (MacPhail \& Kramer, 1995). With respect to effects on EEI scores, in all but one study (Eagleton et al., 2004) PRE resulted in no change (Damiano \& Abel, 1998; Darrah, Wessell, Nearingburg, \& O'Connor, 1999; MacPhail \& Kramer, 1995). Therefore, although PRE interventions appears to have a positive effect on improving levels of muscle strength, effects on aspects of movement function and energy expenditure are not conclusive and require further study.

By improving levels of aerobic capacity, it may be possible to enhance walking economy and motor function through an improved physiological work capacity (Fernandez \& Pitetti, 1993; Dresen, de Groot, Mesa Menor \& Bouman, 1985; Schlough et al. 2005). The effects of aerobic exercise for children with cerebral palsy, however, have not been as thoroughly evaluated as PRE. That being said cycling and arm ergometry studies do suggest that aerobic capacity of children with cerebral palsy may be improved through training (Katsimanis, Evaggelinou, Christoulas, Kandrali, \& Angeloupoulou, 2002; Shinohara Suzuki, Oba, Kawasumi, Kimizuka \& Mita, 2002). Katsimanis et al. (2002) for instance studied the effects of cycling exercise on the aerobic capacity and pulmonary ventilation of seven, 14 to 18 year olds with cerebral palsy. Following 12 weeks, improvements were observed $(\mathrm{p}<0.05)$. Similarly, Shinohara et al. (2002), studied the pre-post effects for arm ergometry versus cycling program for a group of 13 to 15 year olds $(n=11)$. Here, children were assigned to either the cycling or arm ergometry group and exercised at their anaerobic threshold once or twice a week for 6 to 20 weeks. Children performing cycling were found to have significantly improved levels of oxygen consumption $(\mathrm{p}<0.05)$ while no changes were observed in the arm ergometry group.

Two community-based, varied activity programs have also reported the effects of aerobic exercise intervention for children with cerebral palsy using a randomized controlled trial (Dresen et al., 1985; van den Berg-Emons, van Baak, Speth, \& Saris, 1998). The effects of an aerobic training program were evaluated for six 8 to 14 year old children with various diagnoses such as spastic diplegia, spastic hemiplegia, dwarfism and cerebellar ataxia. Results were compared to a control composed of four children with spastic diplegia/hemiplegia (Dresen et al., 1985). Children performed judo, swimming, and game activities, three-times-per-week for a period of 10 weeks. A significant reduction in oxygen consumption levels relative to workload in the aerobic training group was reported, however, no significant between-group differences were found in oxygen consumption levels relative to heart rate.

Effects of two nine-month aerobic training programs have been reported on peak aerobic power for children with cerebral palsy (van Den Berg-Emons et al., 1998). Twenty children, 7 to 12 years old with spastic diplegia or spastic hemiplegia were matched by disability and assigned (randomly) to a training group or a control group. The children exercised four times per week for 45 minutes per session performing cycling, running, swimming, and mat exercises. Following nine months of training, a significant increase in maximal aerobic power was observed for children in the training group compared with controls $(\mathrm{p}<0.01)$. In the following year, children in the control group were invited to participate in the training program with the 
children in the training group (18 children enrolled). The frequency of training for the second portion of the study was reduced to twice-a-week. Aerobic capacity for both the new and former participants did not change significantly following the second nine months of training at a reduced frequency.

In summary, effects of aerobic and strength training interventions for children with cerebral palsy are not well understood and require further investigation to better appreciate the presence and nature of aerobic limitations in children with cerebral palsy, the effectiveness of different forms of intervention, as well as, the parameters that are most effective in promoting a physiological and therapeutic effect.

For these reasons this study was pursued with the question being what effects if any resulted from a community exercise program using both aerobic and strength training components for children with cerebral palsy specific to energy expenditure, muscle strength, and perceived satisfaction and perceived performance of a functional motor goal. The intent of this article then is to describe the program employed for children with cerebral palsy and provide suggestions for similar programs.

\section{METHODOLOGY}

In the fall of 2005, a group of six 8-12 year old children with ambulatory cerebral palsy (able to walk independently >25 meters) participated in four separate ten-week, threetimes-per-week exercise and fitness activity programs. The purpose of the project was to offer aerobic and strength training activity to children with cerebral palsy and to evaluate clinically relevant changes in energy expenditure, muscle strength, and gross motor function.

Participants were invited to participate in the study from a convenience sample. Information was provided about the study to therapists at a local pediatric physical therapy private clinic, the local pediatric hospital, and to therapists providing service to children at local public schools. Therapists were invited to provide the information to children on their case load who fit the inclusion criteria.

Children were eligible for the program if they were 8 to 12 years of age, had a diagnosis of cerebral palsy, walked independently with or without aids for at least five minutes, and were able to follow simple instructions. In addition, their families had to commit to attending the program three-times-a week. Children were excluded from participating if any of the following conditions were present: (a) an increase in regular therapy was anticipated during the study, (b) participation in an aerobic program that occurred more than three times per week, (c) surgery or pharmaceutical intervention was scheduled within six months of the beginning of the study, and/or (d) cardiovascular pathology.

The group received aerobic and strength training interventions for one hour threetimes-a week for 10 weeks. All sessions were held at a community recreation centre, and were led by a pediatric physical therapist. Two to five assistants provided individual assistance to children in the program. Twice-a-week children performed an aerobic and PRE workout, and once-a-week children played in a sport context. The aerobic and PRE workout consisted of a 7-10 minute warm-up, a 30 minute aerobic activity set, a 20 minute PRE circuit, and a 10 minute stretch/cool down.

Children performed a 7 to 10 minute warm-up using traditional exercise equipment. A list of appropriate pieces of up to four pieces of equipment was made for each child based on the size and ability for children to manage independently (stationary bicycles, arm ergometers, steppers, treadmills, and elliptical trainers). Children rotated through the pieces of equipment so that each child exercised on up to four different pieces of equipment throughout the program. Time spent on each of the distinct four pieces of equipment was equal. During the warm-up, children were encouraged to exercise at a level of two to four on the Children's OMNI scale of perceived exertion (Utter, Robertson, Nieman, \& Kang, 2002) and the children were instructed to apply no to minimal resistance during the warm up phase. 
Following the warm-up, children engaged in 30 minutes of aerobic activity. Children were assigned to two pieces of equipment to use for 15 minute each. Throughout each 15 minute period, children were encouraged to exercise between 5 and 7 on the Children's OMNI scale of perceived exertion (Utter et al., 2002) Approximately every 5 to 7 minutes during the aerobic portion of the workout sessions, children were asked to rate their OMNI level. If a child reported an OMNI score of less than 5, the assistant assigned to help the child increased the intensity of the activity by either increasing the speed of activity, or increasing the resistance of the activity. To transition between the two pieces of equipment, children were requested to move as quickly as possible and most transitions took less than 3 minutes.

The OMNI was selected so that the children could reliably monitor their own exercise intensity without having to use the researchers to interpret their current performance and encourage them to exercise at an increased rate. Second, if this intervention were to be carried out in community contexts in the future the authors felt the OMNI would be an easy and reliable means for clinicians to encourage children to exercises at an intensity that would be likely to promote and aerobic effect as it is more clinically relevant and accessible than more expensive and involved forms of technology. Children also wore POLAR heart rate monitors (Polar Electro Inc., Quebec, Canada).

Twenty minutes per session were spent performing PRE. Assistants and the coordinating therapist were available at all sessions to supervise the children performing the exercises, as well, to increase the weight when appropriate. Initially, each child's ten repetition maximum was obtained and the first session was performed with $65 \%$ of the children's ten repetition maximum. Following this, if the child was able to perform three sets of eight repetitions in succession and with good form, his or her weight was increased. Free weights were selected for the program and applied in following strengthening activities: (a) knee extension exercises (performed in sitting with an ankle weight; knee and hip started at 90 degrees, (b) hip abduction exercises (performed in side lying with an ankle weight; the bottom leg started bent and the top leg aligned with the torso, hip, knee, and ankle in neutral position), (c) toe raises (performed one leg at a time with a hand held weight; from standing on one leg, the child was instructed to raise to his/her tiptoes. One to three finger tips were permitted on a ballet bar as required for balance), (d) half squats (performed while standing with a hand held weight; children started standing and were instructed to sit down but not touch the chair behind him/her), (e) step ups (performed one leg at a time with a hand held weight; from standing the child stepped onto block (1 foot high) and stepped up and lowered repeatedly). Finger tip/stand by assistance was provided, as required, for children with balance impairments. Children performed each exercise for eight repetitions, for one to three sets. Between each set the children were provided a one minute rest. Following the resistance activity, children were led through a 7-10 minute cool down and a thorough stretch.

Muscle strength was evaluated using a hand-held dynamometer (Lafayette Instruments, Lafayette, IN, USA). Hand held dynamometer testing is considered a reliable form of muscle testing for individuals with neurological impairments both within and across sessions (Berry, Giulani \& Damiano, 2004) and they have been deemed responsive to change with children with cerebral palsy (Damiano, Vaughan, \& Abel, 1995). Testing procedures were similar to those described in Dodd, Taylor, and Graham (2003) whereby the examiner gradually increased the resistance over the limb for the initial one to two seconds to allow the child to adjust his/her resistance accordingly.

As noted earlier, twice per week the children performed aerobic and strength training activities using traditional weight and cardio equipment. The third day a week involved sport activities. The sport activity day was intended to be fun and motivating for the children. As well, the activities provided a context for children to understand the potential 
benefits of improving their levels of physical fitness. Swimming and cycling were selected as sports for the program based on positive success with the sports in the past, in addition to those sports that were accessible and desired by the participants (Getz, Hutzler \& Vermeer, 2006; Hutzler, Chacham, Bergman, \& Szeinberg, 1998; Shinohara et al., 2002; Thorpe \& Reilly, 2000). Wrestling was selected as one of the three core sports for children in the program because of its playful nature, as well as its proposed effects on body awareness and control. Rock climbing was also added as an additional activity to promote body awareness, control, and promote activity. For all the sports in the program, whenever possible, athletes currently training in the sport were invited to instruct the children. The athlete instructors provided the children examples of their training programs in addition to information on programs currently offered in the surrounding community. In this way, if a child was interested in pursuing the sport further, he or she would have a venue and contact information to do so.

During these sessions, children were encouraged to exercise at or above a level 5 and 7 on the Children's OMNI scale of perceived exertion for at least 20 minutes. Cycling sessions consisted of a 10 minute warm-up, two, 20 minute session of continuous cycling (sprints, mixed standing and seated cycling, mixed one foot and two foot pedaling, and mixed high and low bouts) separated by a $10-15$ minute active stretch and water break, and concluding with a cool-down and stretch. Swim sessions incorporated shallow water aerobics and length swimming into the following schedule: (a) a 10 minute warm-up, (b) a 20 minute aerobic set, (c) a 20 minute length workout, and (d) a 10 minute cool- down and stretch. Rock climbing session mixed a 15 minute treadmill warm-up with bouldering and belayed rock climbing on an indoor rock climbing wall.

Children were then evaluated on clinically accessible measures and were tested individually. Results were compared against his or her own pre-intervention performance. Conventional clinical practice typically involves evaluation of pre-post performance based on single evaluation/test sessions. Although this is the typical convention, clinicians may benefit from evaluating the child over a series of baseline assessments to increase the likelihood of evaluating change in the child's actual performance, thus appreciating that variability day to day and within the measure is possible. For this program, clinical changes were evaluated over a pre-intervention baseline phase and compared with two assessment points collected following the intervention. Assessments were done in clinical environments using clinically accessible tools including the EEI, muscle dynamometry and the GMFM.

Four separate assessments were completed on those variables prior to intervention and graphed. Trend lines, representing the direction of change and magnitude of change, were generated for each phase (baseline, intervention, post-intervention). Significance of change was analyzed using the two-standard deviation bandwidth method. Two-standard deviation bandwidth lines were calculated for the baseline data and extrapolated into the intervention and follow-up phases. If at least two consecutive data points in the intervention phase fell outside of the two-standard deviation range, the change was considered significant because the likelihood of such an event taking place is less than 5 times in 100 (Gottman \& Leiblum, 1974). Stability of baseline measures was evaluated by examination of the slope of the baseline trend line. A slope in the baseline data is problematic, especially if the slope of the intervention trend line is in the same direction. This 'continuing' trend slope makes it impossible to say with certainty that the intervention was responsible for the change in scores because the change was already apparent during baseline when no intervention occurred (Portney \& Watkins, 2000).

The test-retest correlation coefficients of EEI measurements have been reported as 0.81 (Kramer \& MacPhail, 1994) and 0.94 (Wiart \& Darrah, 1999) taken over two sessions with individuals with cerebral palsy. The concurrent validity correlation coefficients have been 
reported between EEI and values of aerobic capacity as 0.61 and 0.66 (Bowen, Lennon, Castagno, Miller, \& Richards, 1998; Norman, Bossman, Gardner, \& Moen, 2004).

Changes in Canadian Occupational Performance Measure (COPM) performance and satisfaction ratings were also examined. For COPM, a change in raw score of two or more was considered to represent a clinically significant change (Law, Baptiste. Carswell, McColl \& Pollock, 1998). This method has been used by other researchers to describe change in single subject design studies (Candler, 2003; Lammi \& Law, 2003).

\section{RESULTS}

\section{Table 1}

Description of the Study Participants

\begin{tabular}{|c|c|c|c|c|}
\hline $\begin{array}{c}\text { Type of } \\
\text { Cerebral palsy }\end{array}$ & Age & $\begin{array}{c}\text { Gross Motor Function } \\
\text { Classification System } \\
\text { Level }\end{array}$ & Activity Level & $\begin{array}{l}\text { Average workout } \\
\text { Heart Rate }\end{array}$ \\
\hline $\begin{array}{l}\text { Spastic } \\
\text { hemiplegia }\end{array}$ & 11 & I & $\begin{array}{l}\text { Sedentary lifestyle; engaged in an active } \\
\text { lifestyle i.e. hiking, walking; not yet } \\
\text { riding bike. }\end{array}$ & 190 \\
\hline Spastic diplegia & 10 & I & $\begin{array}{l}\text { Active child; enjoys sports; learned to } \\
\text { ride a bike one year prior to the start of } \\
\text { this study. }\end{array}$ & 152 \\
\hline Hemiplegia & 8 & $\mathrm{I}$ & $\begin{array}{l}\text { Lifestyle is sedentary; family } \\
\text { encourages engagement in regular bouts } \\
\text { of activity. }\end{array}$ & 132 \\
\hline Spastic diplegia & 9 & $\mathrm{I}$ & $\begin{array}{l}\text { Very active child; enjoyed sports with } \\
\text { peers. }\end{array}$ & 180 \\
\hline Ataxia & 12 & II & $\begin{array}{l}\text { Active lifestyle; regular exercise at } \\
\text { home, skiing, hiking, cycling. }\end{array}$ & 158 \\
\hline $\begin{array}{l}\text { Hypotonia, } \\
\text { hemiplegia }\end{array}$ & 8 & I & Sedentary lifestyle. & 141 \\
\hline
\end{tabular}

A pediatric physical therapist coordinated and supervised all assessments. Assistance was provided from an adapted physical education student for all testing sessions. At each assessment session, the child rested comfortably in supine for five minutes prior to the walking test; the average heart rate of the last two minutes of the five minute period was recorded. After five minutes, the examiner directed the child to the treadmill where the child was instructed to walk continuously as the speed on the treadmill was gradually
Children enrolled in the program for 10 weeks and were evaluated individually on energy expenditure, muscle strength, and perceived satisfaction and perceived performance of a functional motor goal identified by each participant. Following approval from the institutional ethics review board and provision of informed consent, data were collected over three to four sessions during the baseline phase and twice following the 10-week intervention.

The first six children who contacted the primary investigator and satisfied the criteria were included in the study. Descriptive information regarding their activity levels, type of cerebral palsy, and average heart rate achieved during the study is provided in Table one.

Active child; enjoys sports; learned to

Lifestyle is sedentary; family encourages engagement in regular bouts of activity. peers.

Active lifestyle; regular exercise at Sedentary lifestyle.

increased. The child indicated when he/she felt he/she had reached a 'comfortable' walking speed. The average heart rate reading of the last 30 seconds was measured using a Polar Electro heart rate monitors.

Three attempts were taken and the average score of the second and third trial recorded. Muscle strength for plantar flexion, knee extension and hip extension were measured using the positions described in table 2 . Strength for the left and right sides were measured separately. 
Table 2

Isometric strength test positions

\begin{tabular}{|c|c|c|c|}
\hline Muscle group & Body position & Joint position & $\begin{array}{l}\text { Dynamometer } \\
\text { Placement }\end{array}$ \\
\hline Ankle plantarflexors & Supine on plinth & $\begin{array}{l}\text { Knee flexed to } 90 \text { degrees, } \\
\text { lower leg stabilized }\end{array}$ & $\begin{array}{l}\text { Across the metatarsal } \\
\text { heads }\end{array}$ \\
\hline Knee extensors & $\begin{array}{l}\text { Sitting on plinth (no back } \\
\text { rest) }\end{array}$ & Knee flexed to 90 degrees & $\begin{array}{l}2 \mathrm{~cm} \text { proximal from the } \\
\text { base of the lateral } \\
\text { malleolus }\end{array}$ \\
\hline Hip extensors & $\begin{array}{l}\text { Prone, hip at the edge of the } \\
\text { plinth }\end{array}$ & $\begin{array}{l}\text { Hip at } 45 \text { degrees, pelvis } \\
\text { stabilized }\end{array}$ & $\begin{array}{l}\text { Posterior thigh, } 1 / 4 \text { thigh } \\
\text { proximal from the knee } \\
\text { joint }\end{array}$ \\
\hline
\end{tabular}

The authors targeted exercises that were known to be weak for children with cerebral palsy, and related to where there was some evidence of association with functional activity. Although the authors did test muscles in isolation, they also incorporated both isolated movement strengthening as well as functional exercise movements with the intent of maximizing both the increase in specified weak muscles, as well as enhance strength in movements that are thought to be associated with functional activities (Fowler et al, 2007).

EEI measures were recorded three to four times during a three-week baseline and twice following intervention and were taken while the children walked on a treadmill.

Figure 1. Energy Expenditure Index Scores for Child 1 through 6.

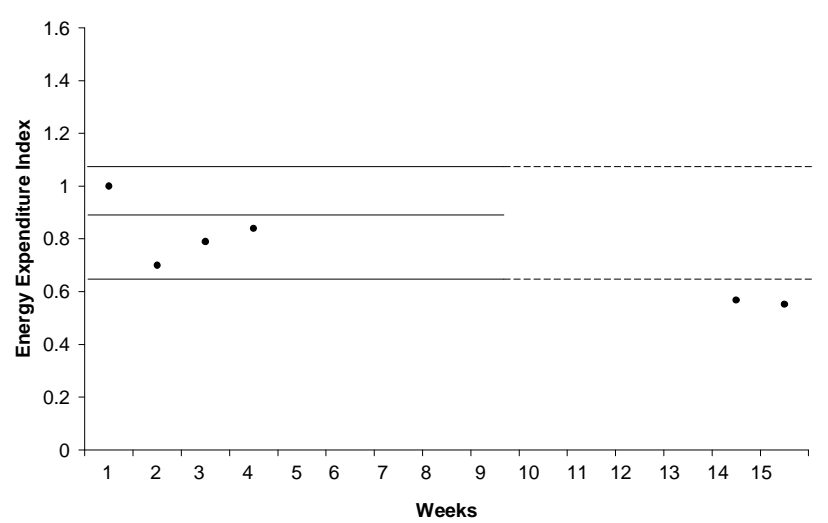

Energy Expenditure Index Scores for Child 1

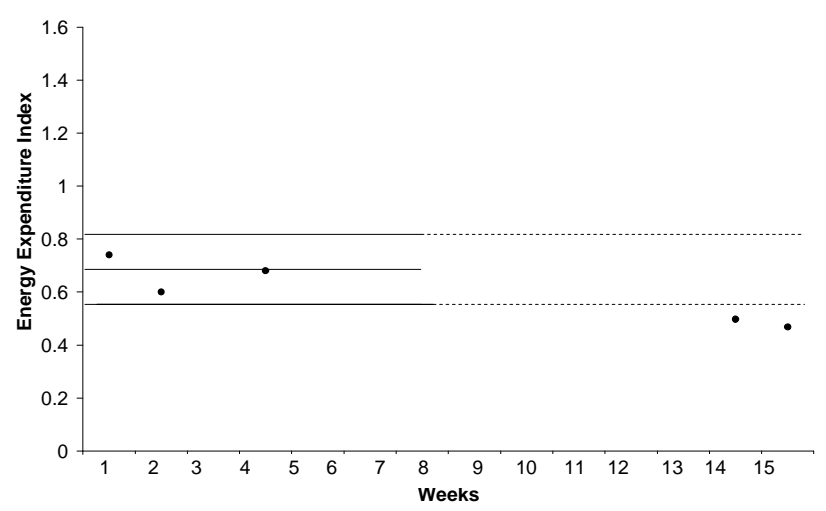

Energy Expenditure Index Scores for Child 3

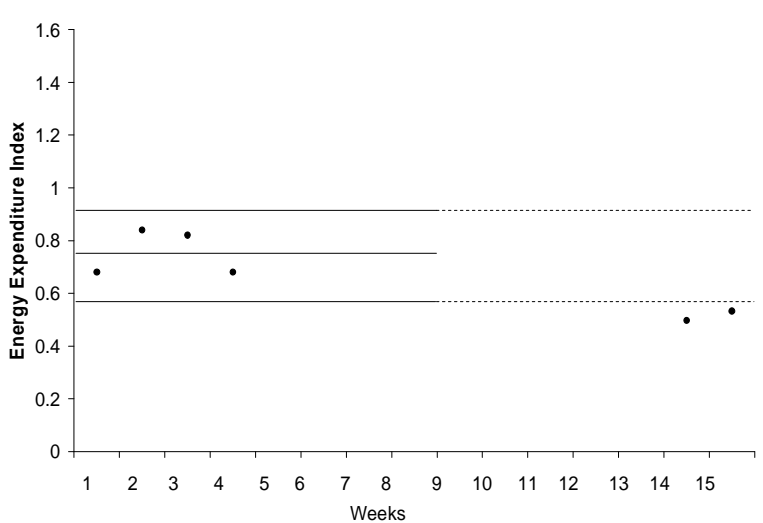

Energy Expenditure Index Scores for Child 2

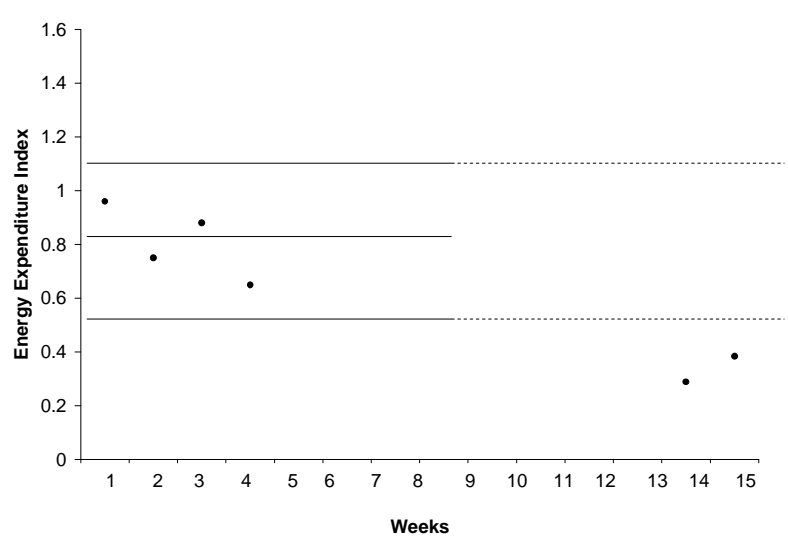

Energy Expenditure Index Scores for Child 4 


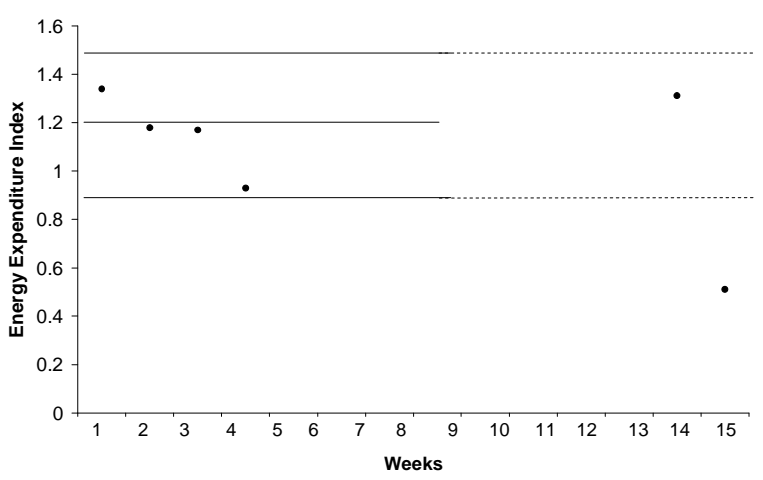

Energy Expenditure Index Scores for Child 5

The mean EEI scores for all six children in the study was lower following intervention that during baseline. Two data points fell below the standard deviation bandwidth during the post intervention stage for four of the six children (child 1 through 4) indicating improvements were better than the criterion level we set for demonstrating the effect of the independent variable. For Child 4, however, a downward trend was present in the baseline phase and therefore it cannot be assumed that the improved EEI scores reflect change due to the intervention. Scores were consistent with the range of those described in

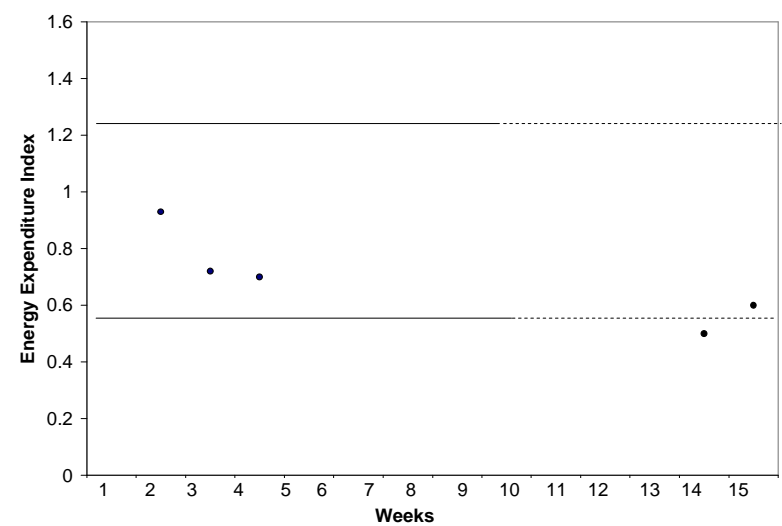

Energy Expenditure Index Scores for Child 6

previous studies for children with similar types of cerebral palsy (Ijzerman \& Nene, 2002; Keefer, Tseh, Caupto, Apperson, McGreal, \& Morgan, 2004; Rose, Haskell, Gamble, Hamilton, Brown, \& Rinsky, 1994; Rose et al., 1985).

Table 3 outlines COPM raw scores for five children. One child could not complete the questions owing to a lack of understanding of the rating scale. COPM scores for all children who completed the questions changed by two or more from baseline to intervention.

Table 3

COPM Performance and Satisfaction Scores

\begin{tabular}{|c|c|c|c|c|}
\hline & & & \multicolumn{2}{|c|}{ COPM Score } \\
\hline Child & Goal & & Baseline & Post-intervention \\
\hline \multirow[t]{2}{*}{1} & \multirow[t]{2}{*}{ Shooting a basketball } & Performance & 5 & 7 \\
\hline & & Satisfaction & 2 & 8 \\
\hline \multirow[t]{2}{*}{2} & \multirow{2}{*}{$\begin{array}{l}\text { Walking downstairs } \\
\text { with no hands }\end{array}$} & Performance & 4 & 10 \\
\hline & & Satisfaction & 6 & 8 \\
\hline \multirow[t]{2}{*}{3} & \multirow[t]{2}{*}{ Run Faster } & Performance & 1 & 10 \\
\hline & & Satisfaction & 5 & 10 \\
\hline \multirow[t]{2}{*}{4} & \multirow[t]{2}{*}{ Run Faster } & Performance & 7 & 9 \\
\hline & & Satisfaction & 8 & 10 \\
\hline \multirow[t]{2}{*}{5} & \multirow[t]{2}{*}{ Run Faster } & Performance & 4 & 8 \\
\hline & & Satisfaction & 3 & 10 \\
\hline
\end{tabular}

Changes in muscle strength were variable across children in the program. Change beyond chance were observed for Child 1 with respect to bilateral knee extension, and the right plantar flexion; for Child 2 with respect to bilateral knee and hip extension; for Child 4 with respect to the left side plantar flexion and knee extension as well as for bilateral for hip extension; and for Child 6 with respect to bilateral ankle plantar flexion and knee extension. Changes observed for Child 3 and Child 5 did not exceed that which could be attributed to chance. 
Table 4

Pre and post-intervention strength values.

\begin{tabular}{|c|c|c|c|c|c|c|}
\hline Child & Muscle & $\begin{array}{l}\text { Baseline } \\
\text { Range }\end{array}$ & $\begin{array}{l}2 \text { Standard } \\
\text { deviation }\end{array}$ & $\begin{array}{l}\text { Post- } \\
\text { analysis } 1\end{array}$ & $\begin{array}{l}\text { Post- } \\
\text { analysis } 2\end{array}$ & Change beyond chance? \\
\hline \multirow[t]{6}{*}{1} & PFL & $6.2-8.9$ & $4.9-10.8$ & 10 & $13.4^{*}$ & No \\
\hline & PFR & $5.4-9.6$ & $3.3-11.7$ & $12 *$ & $12.6^{*}$ & Yes \\
\hline & KEL & $9.2-13.5$ & $5.8-15.6$ & $16.8 *$ & $17 *$ & Yes \\
\hline & KER & $10.4-12.7$ & $8.5-13.8$ & $18.1 *$ & $16.5 *$ & Yes \\
\hline & HEL & $10.4-13.7$ & $8.2-15.2$ & 13.8 & $16.5^{*}$ & No \\
\hline & HER & $10-13.3$ & $7.5-14.9$ & 12.6 & $16.6^{*}$ & No \\
\hline \multirow[t]{6}{*}{2} & PFL & $4.23-7.8$ & $1.0-11.1$ & $12.3 *$ & $14.8 *$ & Yes \\
\hline & PFR & $3.8-5.7$ & $2.1-7.4$ & $8.6^{*}$ & $8.85^{*}$ & Yes \\
\hline & KEL & $10.2-10.4$ & $10-10.6$ & $17.2 *$ & $23.1 *$ & Yes \\
\hline & KER & $11.0-13.0$ & $9.2-14.8$ & $16.9 *$ & $23.5^{*}$ & Yes \\
\hline & HEL & $9.0-10.1$ & $8.0-11.1$ & $17.4 *$ & $25.5 *$ & Yes \\
\hline & HER & $8.1-8.8$ & $7.5-9.4$ & $15.2 *$ & $14.5^{*}$ & Yes \\
\hline \multirow[t]{6}{*}{3} & PFL & $4.2-6.2$ & $1.4-7.1$ & $12.3 *$ & 3.3 & No \\
\hline & PFR & $3.8-17.1$ & $-10.1-17.7$ & 8.6 & 7.9 & No \\
\hline & KEL & $7.5-12.5$ & $3.1-17.3$ & 17.2 & 7.4 & No \\
\hline & KER & $11.0-18.38$ & $3.2-18.9$ & 16.9 & 8.05 & No \\
\hline & HEL & $9.0-10.6$ & $6.8-11.2$ & $17.4^{*}$ & 6.6 & No \\
\hline & HER & $8.1-10.5$ & $6.9-9.3$ & $15.2 *$ & 6.1 & No \\
\hline \multirow[t]{6}{*}{4} & PFL & $4.1-6.2$ & $3.5-4.7$ & $14.4 *$ & $12.6 *$ & Yes \\
\hline & PFR & $3.7-17.1$ & $-10.9-19.3$ & 11.2 & 8.9 & No \\
\hline & KEL & $7.4-11.1$ & $6.7-8.1$ & $15.4 *$ & $22.9^{*}$ & Yes \\
\hline & KER & $9.5-19$ & $-1.8-20.8$ & 17.3 & 24.7 & No \\
\hline & HEL & 7.6-10.5 & $4.5-10.7$ & $14.3 *$ & $20 *$ & Yes \\
\hline & HER & $8-10.6$ & $6.44-9.6$ & $16.7 *$ & $21 *$ & Yes \\
\hline \multirow[t]{6}{*}{5} & PFL & $6.4-7.6$ & $5.9-9.3$ & $14.6 *$ & 7 & No \\
\hline & PFR & $6.2-6.4$ & 5.9-.6.5 & $16.3 *$ & 6 & No \\
\hline & KEL & $8.3-9$ & $7.3-9.3$ & $17.3^{*}$ & 8.5 & No \\
\hline & KER & $10-11.5$ & $7.9-12.1$ & $21.2 *$ & 11 & No \\
\hline & HEL & $6.7-9$ & $3.4-10.0$ & $14.3 *$ & 6.4 & No \\
\hline & HER & $7-9$ & $4.2-9.8$ & $17.8 *$ & 6.4 & No \\
\hline \multirow[t]{6}{*}{6} & PFL & $7.6-8.0$ & $7.2-8.0$ & $24.05^{*}$ & $14.3 *$ & Yes \\
\hline & PFR & $6.2-8$ & $4.22-8.2$ & $16.3^{*}$ & $16.8 *$ & Yes \\
\hline & KEL & $8.3-11.1$ & $5.4-11.1$ & $17.3 *$ & $17 *$ & Yes \\
\hline & KER & $9.1-10.5$ & $8.6-11.4$ & $21.2 *$ & $22.6 *$ & Yes \\
\hline & HEL & $6.7-7.9$ & $5.5-7.9$ & $14.3 *$ & 8.0 & No \\
\hline & HER & $7-7.8$ & $6.1-7.9$ & $17.8 *$ & $9.8 *$ & Yes \\
\hline
\end{tabular}

Overall the program was well received by the families. All families expressed interest in continuing the program following its conclusion and spurred the inception of a sports and training-based program in the local area.

\section{DISCUSSION}

All six children in the program demonstrated improvements in the mean levels of their EEI scores pre to post intervention, three of which met the criteria for demonstrating an effect from a research perspective (change beyond chance). This offers support for future investigation to explore the potential for aerobic and strength training interventions to improve energy expenditure index scores in children with cerebral palsy.

Three of the children failed to demonstrate a sustained change in EEI scores 
post-intervention. One of these children (Child 5) took a two week vacation just prior to testing and missed six sessions at the conclusion of the program returning in time for follow-up testing. Although it is not possible to know whether the lack of change is a result of a lack of training or otherwise, the incident and its potential effect are recognized. This same child demonstrated limited change in muscle strength and motor function as well, which may have resulted from his not being a part of programming for the last six sessions. The reason for the lack of change in Child 6, however, is unknown. For both Child 3 and Child 6, average exercise heart rates were lower than the recommended target heart rate of 150 beats per minute suggested by the American Academy of Pediatrics (AAP) (Dyment, 1991). Unlike Child 3, however, Child 6 missed approximately $25 \%$ of sessions owing to illness. As well, the majority of research involving exercise effects for children with cerebral palsy has involved children with spastic diplegia or hemiplegia (Taylor et al., 2005; Darrah \& Kelly, 2005). Thus Child 5 having a diagnosis of ataxia and Child 6 , a diagnosis of hypotonia may have influenced these results. Although it was the researcher's hypothesis that children would improve their EEI scores through training, it may be that exercise has different effects for children with different presentations of cerebral palsy.

The downward trending was problematic when interpreting the EEI data for Child 4, 5, and 6. Influences of other factors such as anxiety (Maltais, Bar-Or, Galea, \& Pierrynowski, 2001) may have contributed to alterations in the EEI score without true change in the child's efficiency. Second, measures such as the EEI are popular in the absence of an affordable and clinically accessible alternative, however, the EEI may not be as sensitive to small changes in children's aerobic performance as more technical laboratory measures such as oxygen consumption (Bowen et al., 1998; Keefer et al., 2004). Because the EEI involves measuring heart rate, other factors that influence heart rate aside from improvements in energy expenditure and thus a more sensitive measure of energy exenditure may have detected smaller, more discrete changes in energy expenditure in the chldren in this study with less influence from external factors. As well, although a repeated measures baseline was used to help reduce risks associated with intra-individual test variability, the researchers did not provide opportunity for the children to familiarize with the testing procedures prior to collecting data which may have increased anxiety as noted earlier. Allowing time for children to become accustomed to the testing equipment and protocol may help reduce this effect.

Muscle strength outcomes were variable within and across children. No changes were observed in Child 3 and 5. As noted previously, Child 5 was away on vacation for the six sessions prior to testing. Although the score appears to have changed quite significantly for the first follow-up test, there were no detectable changes by the second week of testing. Results for Child 3 are variable. This child struggled to cooperate with the PRE portion of the program having difficulty performing the required number of exercises with sufficient resistance.

The different responses in muscle strength across children may also be a result of measurement error. In a recent review of the reliability of muscle dynamometer testing, Crompton, Gallea and Phillips (2007) identified poor between-session reliability for hip extensors, knee extensors and plantar flexors. Evaluating effects of a smiliar program on muscle strength using a more reliable measure would assist in better understanding of these effects.

In our study, the same program was employed by all children and overall the effects on muscle strength were variable. It may be more appropriate to target muscle groups in terms of children's weaknesses, or, in relation to muscle groups involved in activities the child identifies as his/her functional goals and both of these strategies have been used in previous PRE studies. Damiano and Abel (1998), for instance, targeted two of the child's weakest lower 
extremity muscles and Schlough et al. (1999) targeted muscles involved in gait.

With regards to the COPM, improvements were noted for all children (see table 3). Changes in self-perception have been reported in past studies following exercise programs involving individuals with cerebral palsy (Darrah et al., 1999; Schlough et al., 2005) and further evaluation of the relationships between perceived performance of gross motor skill and actual performance of motor function would further inform clinical practice in better understanding the potential implications of fitness interventions.

Anecdotally, parents reported that children had fun in the program and were pleased with improvements in confidence, strength, and flexibility. Some parents commented on their struggle to commit to the intense schedule, particularly in light of having to travel through rush hour traffic. All parents in the program, however, requested information regarding continuation of community sport and fitness programs and were instrumental in forming a sport and fitness program the following year. Six months following, $100 \%$ of the children in this study reported being enrolled in a fitness and/or sport program offered two to three times per week.

\section{CONCLUSION}

Exercise programs for persons with cerebral palsy have been used widely as it relates to sport performance. Less common, however have been exercise programs for children for purposes other than sport training, although as noted earlier, they are gaining popularity among adaptive physical education and rehabilitation practitioners. Within these existing programs and related studies the majority has been dealt with the effects of strength training while less have addressed the effects of aerobic exercise with even fewer addressing both.

Clinical evaluations of such programs would be helpful to better understand the effects and guide future programming and thus in this study, the value and benefit of aerobic and strength training exercise was presented focusing specifically on land based programs. This will hopefully lead to greater interest in creating and evaluating these types of programs and thereby increase the opportunities available for persons with cerebral palsy for both sport and recreational pursuits.

\section{REFERENCES}

American Academy of Pediatrics (2003). Prevention of pediatric overweight and obesity. Pediatrics, 112, 424-430.

Berry, E., Giuliani, C., \& Damiano, D. (2004). Intra-session and intersession reliability of handheld dynamometry in children with cerebral palsy. Pediatric Physical Therapy, 16, 191-198.

Bowen, T.R., Lennon, N., Castagno, P., Miller, F., \& Richards, J. (1998). Variability of energy-consumption measures in children with cerebral palsy. Journal of Pediatric Orthopedics, 18, 738-742.

Candler, C. (2003). Sensory integration and therapeutic riding at summer camp: occupational performance outcomes. Physical and Occupational Therapy Pediatrics, 23, 51-64.

Canadian Pediatric Society (2002). Healthy active living for children and youth. Pediatric Child Health, 7, 339-345.

Crompton J., Galea M.P., Phillips B. (2007). Hand-held dynamometry for muscle strength measurement in children with cerebral palsy. Developmental Medicine and Child Neurology, 49, 106-11.

Damiano, D.L., Vaughan, C.L., Abel, M.F. (1995). Muscle response to heavy resistance exercise in spastic cerebral palsy. Developmental Medicine and Child Neurology, 37, 731-739.

Damiano, D.L, \& Abel, M.F. (1998). Functional outcomes of strength training in spastic cerebral palsy. Archives of Physical Medicine and Rehabilitation, 79, 119-125.

Darrah, J., \& Kelly, M. (2005). Aerobic Exercise for Children. Physiotherapy Canada, 58, 187195.

Darrah, J., Wessel, J., Nearingburg, P., \& O'Connor, M. (1999). Evaluation of a community fitness program for adolescents 
with cerebral palsy. Pediatric Physical Therapy, 11, 18-23.

Dodd, K.J, Taylor, N.F, \& Graham, H.K. (2003). A randomized clinical trial of strength training in young people with cerebral palsy. Developmental Medicine and Child Neurology, 45, 652-657

Dresen, M.H., de Groot, G., Mesa Menor, J.R., \& Bouman, L.N. (1985). Aerobic energy expenditure of handicapped children after training. Archives of Physical Medicine and Rehabilitation, 66, 302-306.

Dyment, P. ( 1991). Sports Medicine: Health Care for Young Athletes (2nd ed.). Elk Grove Village: American Academy of Pediatrics.

Eagleton, M., Iams, A., McDowell, J., Morrison, R., \& Evans, C.L. (2004). The effects of strength training on gait in adolescents with cerebral palsy. Pediatric Physical Therapy, 16, 22-30.

Fernandez, J.E., \& Pitetti, K.H. (1993). Training of ambulatory individuals with cerebral palsy. Archives of Physical Medicine and Rehabilitation, 74, 468-472.

Fowler, E., Kolobe, T., Damiano, D., Thorpe, D., Morgan, D., Brunnstrom, J. (2007). Promotion of physical fitness and prevention of secondary conditions for children with cerebral palsy: Pediatrics research summit proceedings, 87, 14951510.

Getz, M., Hutzler, Y., \& Vermeer, A. (2006). Effects of aquatic interventions in children with neuromotor impairments: a systematic review of the literature. Clinical Rehabilitation, 20, 927-936.

Gottman, J. M., \& Leiblum, S. R. (1974). How to do psychotherapy and how to evaluate it: A manual for beginners. New York: Holt, Rinehart \& Winston.

Hutzler, Y., Chacham, A., Bergman, U., \& Szeinberg, A. (1998). Effects of a movement and swimming program on vital capacity and water orientation skills of children with cerebral palsy. Developmental Medicine and Child Neurology, 40, 176181.

Ijzerman, M.J., \& Nene, A.V. (2002). Feasibility of the physiological cost index as an outcome measure for the assessment of energy expenditure during walking. Archives of Physical Medicine and Rehabilitation, 83, 1777-1782.

Katsimanis, G., Evaggelinou, C.H., Christoulas, K., Kandrali, I., \& Angelopoulou, N. (2002, July 24-28). Using a training program to enhance the aerobic power in young individuals with spastic diplegia (abstract). Paper presented at the $7^{\text {th }}$ annual congress of the European College of Sport Science, Athens, Greece.

Keefer, D.J., Tseh, W., Caputo, J.L., Apperson, K., McGreal, S., \& Morgan, D.W. (2004). Comparison of direct and indirect measures of walking energy expenditure in children with hemiplegic cerebral palsy. Developmental Medicine and Child Neurology, 46, 320-324.

Kramer, J. F., \& MacPhail, H. E. A. (1994). Relationships among measures of walking efficiency, gross motor ability, and isokinetic strength in adolescents with cerebral palsy. Pediatric Physical Therapy, $6,3-8$.

Lammi, B. M., \& Law, M. (2003). The effects of family-centered functional therapy on the occupational performance of children with cerebral palsy. Canadian Journal of Occupational Therapy, 70, 285-297.

Law, M., Baptiste, S., Carswell, A., McColl, M. P. H., \& Pollock, N. (1998). The Canadian Occupational Performance Measure. Ottawa, Ontario: CAOT Publications.

MacPhail, H.E., \& Kramer, J.F. (1995). Effect of isokinetic strength-training on functional ability and walking efficiency in adolescents with cerebral palsy. Developmental Medicine and Child Neurology, 37, 763775.

Maltais, D., Bar-Or, O., Galea, V., \& Pierrynowski, M. (2001). Use of orthoses lowers the $\mathrm{O}(2)$ cost of walking in children with spastic cerebral palsy. Medicine and Science in Sports and Exercise, 33, 320325.

Norman, J.F., Bossman, S., Gardner, P., \& Moen, C. (2004). Comparison of the energy expenditure index and oxygen consumption 
index during self-paced walking in children with spastic diplegia cerebral palsy and children without physical disabilities. Pediatric Physical Therapy, 16, 206-211 .

Portney, L.G., \& Watkins, M.P. (2000). Foundations of Clinical Research: Applications to Practice (2nd ed.). New Jersey: Prentice Hall Health.

Rose, J., Haskell, W.L., Gamble, J.G., Hamilton, R.L., Brown, D.A., \& Rinsky, L. (1994). Muscle pathology and clinical measures of disability in children with cerebral palsy. Journal of Orthopaedic Research, 12, 758-768.

Rose, J., Medeiros, J.M., \& Parker, R. (1985). Energy cost index as an estimate of energy expenditure of cerebral-palsied children during assisted ambulation. Developmental Medicine and Child Neurology, 27, 485490.

Schlough, K., Nawoczenski, D., Case, L.E., Nolan, K., \& Wigglesworth, J.K. (2005). The effects of aerobic exercise on endurance, strength, function and selfperception in adolescents with spastic cerebral palsy: a report of three case studies. Pediatric Physical Therapy, 17, 234-250.

Shinohara, T.A., Suzuki, N., Oba, M., Kawasumi, M., Kimizuka, M., \& Mita, K. (2002). Effect of exercise at the AT point for children with cerebral palsy. Bulletin of the Hospital for Joint Diseases, 61(1-2), 63-67.

Strauss, D., Cable, W., \& Shavelle, R. (1999). Causes of excess mortality in cerebral palsy. Developmental Medicine and Child Neurology, 41, 580-585.

Taylor, N.F., Dodd, K.J., \& Damiano, D.L. (2005). Progressive resistance exercise in physical therapy: a summary of systematic reviews. Physical Therapy, 83, 1208-1223.

Thorpe, D.E., \& Reilly, M. (2000). The effect of an aquatic resistive exercise program on lower extremity strength, energy expenditure, functional mobility, balance and self perception in an adult with cerebral palsy: a retrospective case report. Journal of Aquatic Physical Therapy, 8(2), 18-24.

Utter, A.C., Robertson, R. J., Nieman, D.C., \& Kang, J. (2002). Children's OMNI Scale of Perceived Exertion: walking/running evaluation. Medicine and Science in Sports and Exercise, 34, 139-144

van den Berg-Emons, H.J., Saris, W.H., de Barbanson, D.C., Westerterp, K.R., Huson, A., \& van Baak, M.A. (1995). Daily physical activity of schoolchildren with spastic diplegia and of healthy control subjects. Journal of Pediatrics, 127, 578584.

van den Berg-Emons, R.J., Van Baak, M.A., Speth, L., \& Saris, W.H. (1998). Physical training of school children with spastic cerebral palsy: effects on daily activity, fat mass and fitness. International Journal of Rehabilitation Research, 21, 179-194.

Wiart, L., \& Darrah, J. (1999). Test-retest reliability of the energy expenditure index in adolescents with cerebral palsy. Developmental Medicine and Child Neurology, 41, 716-718.

Corresponding author's e-mail address: dlegg@mtroyal.ca 


\section{GRUPPENBASIERTES AUSDAUER- UND KRAFTTRAININGSPROGRAMM FÜR KINDER MIT CEREBRALER BEWEGUNGSSTÖRUNG}

(Resümee)

Es gibt wissenschaftliche Studien zu den Effekten von Krafttraining auf Kinder mit cerebraler Bewegungsstörung, jedoch existieren große Lücken hinsichtlich unseres Verständnisses über das Ausmaß der aeroben Einschränkungen und der Effekte von Training auf diese Funktion. Ebenso gibt es einen Mangel an Forschung über Auswirkungen von kombinierten Interventionen, die sowohl Kraft als auch Ausdauertraining mit einschließen. Aus diesen Gründen wurde diese Studie durchgeführt mit der Frage nach den Auswirkungen. Spezifisch wurden Daten über den Energieverbrauch, die Muskelkraft sowie zur empfundener Zufriedenheit und wahrgenommenen Erbringung eines körperlichen Leistungsziels erhoben, die sich infolge eines GruppenÜbungsprogramms, das sich aus sowohl aeroben wie anaeroben Komponenten für Kinder mit cerebraler Bewegungsstörung zusammensetzte, ergaben. Sechs Kinder zwischen 8-12 Jahren mit Cerebralparese, aber gehfähig (können mehr als 25 Meter allein gehen) nahmen in vier separaten Perioden an einem Übungs- und Fitnessprogramm teil, das über 10 Wochen 3 mal pro Woche stattfand. Alle sechs Kinder zeigten Verbesserungen hinsichtlich Energieverbrauch und wahrgenommener Zufriedenheit, während die Werte zur Muskelkraft sehr verschieden ausfielen. Diese Ergebnisse stellen eine Basis für zukünftige Untersuchungen zur Erforschung der Potenziale für Ausdauer- und Krafttrainings-Interventionen bei Kindern mit cerebraler Bewegungsstörung dar.

SCHLÜSSELWÖRTER: Ausdauer, Kraft, Übung, Training, und cerebrale Bewegungsstörung.

\section{PROGRAMME D'ENTRAINEMENT EN AEROBIE ET SUR LA FORCE POUR DES ENFANTS IMC, BASE SUR LA COMMUNAUTE}

(Résumé)

Des recherches ont été menées sur les effets d'entraînement de renforcement musculaire pour des enfants atteints d'infirmité motrice cérébrale, toutefois il reste de grandes lacunes dans notre compréhension de la nature des limitations aérobies et concernant les effets de l'exercice sur des interventions combinées impliquant à la fois un entraînement sur la force et le processus aérobie. Pour ces raisons, cette étude a été conduite avec la question de déterminer quels sont les effets, liés à la dépense d'énergie, à la force musculaire, à la satisfaction perçue et à la performance perçue d'une objectif fonctionnel et moteur résultant d'un programme d'exercice au sein de la communauté, en utilisant à la fois des composants aérobie et anaérobie pour des enfants IMC . Six enfants IMC de 8-12 ans, ambulatoires (capables de marcher de façon autonome> 25 mètres) ont participé à des programmes d'activités de fitness quatre à dix semaines, trois fois par semaine. Les six enfants ont montré des améliorations de la dépense énergétique et de la satisfaction perçue alors que les évaluations ont été variables pour la force musculaire. Ces résultats concourent à soutenir de futures investigations visant à explorer les effets de programmes d'interventions sur le processus aérobie et sur la force d'enfants IMC.

MOTS CLEFS : Aérobie, force, exercice, entraînement, infirmité motrice cérébrale. 